\title{
PROPOSED USE OF THE T PHASE IN TSUNAMI WARNING SYSTEMS*
}

\author{
By Maurice Ewing, Ivan Tolstoy, and Frank Press
}

\begin{abstract}
A stRIKING correlation between the occurrence of a short-period earthquake phase ( $T$ phase) traveling through the ocean with the speed of sound in sea water and the occurrence of tsunamis has been observed. The characteristics of the $T$ phase are described and the data upon which the correlation is based are presented. Although further study is needed, the evidence at hand warrants the inclusion of instruments suitable for recording the $T$ phase in tsunami warning systems. It is quite possible that SOFAR listening stations would be valuable adjuncts in the detection of tsunami-producing earthquakes since they offer the best means of recording the $T$ phase.
\end{abstract}

\section{INTRODUCTION}

The $T$ PHAse in earthquake seismograms was first identified by Tolstoy and Ewing $^{1}$ in 1948 as a compressional wave propagated through the ocean. It had previously been observed by Linehan ${ }^{2}$ in the Weston records of earthquakes in the West Indian region. Linehan stated that it probably was a new phase, but he did not undertake to determine the path or mechanism of propagation involved. In our recent work the $\mathrm{T}$ phase was observed on the Benioff short-period instruments at Weston, Fordham, and Ottawa, and on the WoodAnderson seismographs at Seven Falls and Shawinigan Falls for a series of major and minor Dominican Republic shocks. In addition the $\mathrm{T}$ phase was observed on the Benioff short-period seismograms of the Pasadena network of stations, the Mount Hamilton and Mineral stations, and on the NeumannLabarre at Honolulu for a series of major Japanese and Aleutian shocks.

\section{Description of the T Phase}

For a complete description of the $T$ phase, the reader is referred to the report of Tolstoy and Ewing. ${ }^{3}$ Only a brief summary is given here.

The $T$ phase is characterized by periods of 0.5 sec. or less, a velocity identical with that of sound in water for the part of its path crossing deep water and by speeds from 12,000 to $18,000 \mathrm{ft} / \mathrm{sec}$. ( 3.7 to $5.5 \mathrm{~km} / \mathrm{sec}$.) across shallow water or land.

* Manuscript received for publication May 31, 1949.

The research reported in this document has been made possible through support and sponsorship extended by the Geophysical Research Directorate of the Cambridge Field Station, AMC, U.S. Air Force, under Contract W-28-099 ac-396. It is published for technical information only and does not represent recommendations or conclusions of the sponsoring ageney.

I Ivan Tolstoy and Maurice Ewing, "The T Phase of Shallow-Focus Earthquakes," Bull. Seism. Soc. Am., 40:25-51 (1950).

"Daniel Linehan, "Earthquakes in the West Indian Region," Am. Geophys. Union, Trans., pp. 229-232 (1940).

3 Tolstoy and Ewing, loc. cit. 
The amplitude of the $T$ phase decays much more rapidly over land than that of other phases. For small amplitudes due either to weak shocks or propagation over land the duration of the $\mathrm{T}$ phase decreases and the apparent travel time increases, until for very small amplitudes only a very small and short signal is visible. The ground motion of the $\mathrm{T}$ phase is complex. At Weston it appears as a series of successive $\mathrm{P}$ and SV-SH arrivals, the transverse components being particularly large.

Conditions are very favorable for propagation of the $\mathrm{T}$ phase from epicenters off the north coast of the Dominican Republic to stations on the east coast of the United States, $T$ having been observed with large amplitude for a large number of major and minor shocks. Conditions are less favorable for Pacific Coast stations, since only shocks of magnitude 7 or over produce smallamplitude $\mathrm{T}$ phases.

\section{Method of Propagation of T Phase}

Press and Ewing 4 have treated the propagation of sound in a liquid layer overlying an infinite solid, generalizing the work of Pekeris ${ }^{5}$ in which the underlying medium is a liquid. These calculations provide the theory for sound propagation in an ocean with either a solid or a liquid bottom. In both cases it is shown that short-period oscillations, traveling with the speed of sound in the water, can be transmitted over great distances.

This theoretical result explained the observations of Worzel and Ewing, ${ }^{6}$ who found high-frequency waves propagated at the speed of sound in water from explosions in shallow water. The shallow-water experiments may be considered as scale models for the study of propagation across deep water, leading one to expect a corresponding phase for earthquake waves traveling oceanic paths. This type of propagation will be referred to as normal mode propagation.

In the work just described, the velocity of sound was taken to be independent of depth in the water. Actually, in the deep ocean the velocity of sound has a minimum value at 400 to 700 fathoms, and the work of Ewing and Worzel ${ }^{7}$ on the SOFAR sound channel has shown that sounds originating from a small bomb near the depth of minimum sound velocity will travel across the ocean with very little attenuation. In the SOFAR experiments the wave lengths used were all so short that propagation could be represented by rays refracted back and forth across the sound channel. This type of propagation will be referred to as sound-channel propagation.

\footnotetext{
${ }^{4}$ Frank Press and Maurice Ewing, "A Theory of Microseisms with Geological Applications" Trans. Am. Geophys. Union, Vol. 29, No. 2, pp. 163-174 (1948).

5 C. L. Pekeris, "Theory of Propagation of Explosive Sounds in Shallow Water," in Propagation of Sound in the Ocean, Geol. Soc. Am., Mem. No. 27 (1948).

$6 \mathrm{~J}$. L. Worzel and Maurice Ewing, "Explosive Sounds in Shallow Water," ibid.

7 Maurice Ewing and J. L. Worzel, "Long-Range Sound Transmission," ibid.
} 
Knowledge of the frequency spectrum of the $\mathrm{T}$ phase is scanty owing to instrumental limitations, but the available data give a predominant period somewhat less than 0.5 sec., which falls in the region where transition from sound-channel to normal-mode transmission takes place. It is probable that with suitable instruments both types of transmission can be detected and the transition from one type to the other studied in detail.

TABLE 1

Pacific Tsunamis, 1933-1948

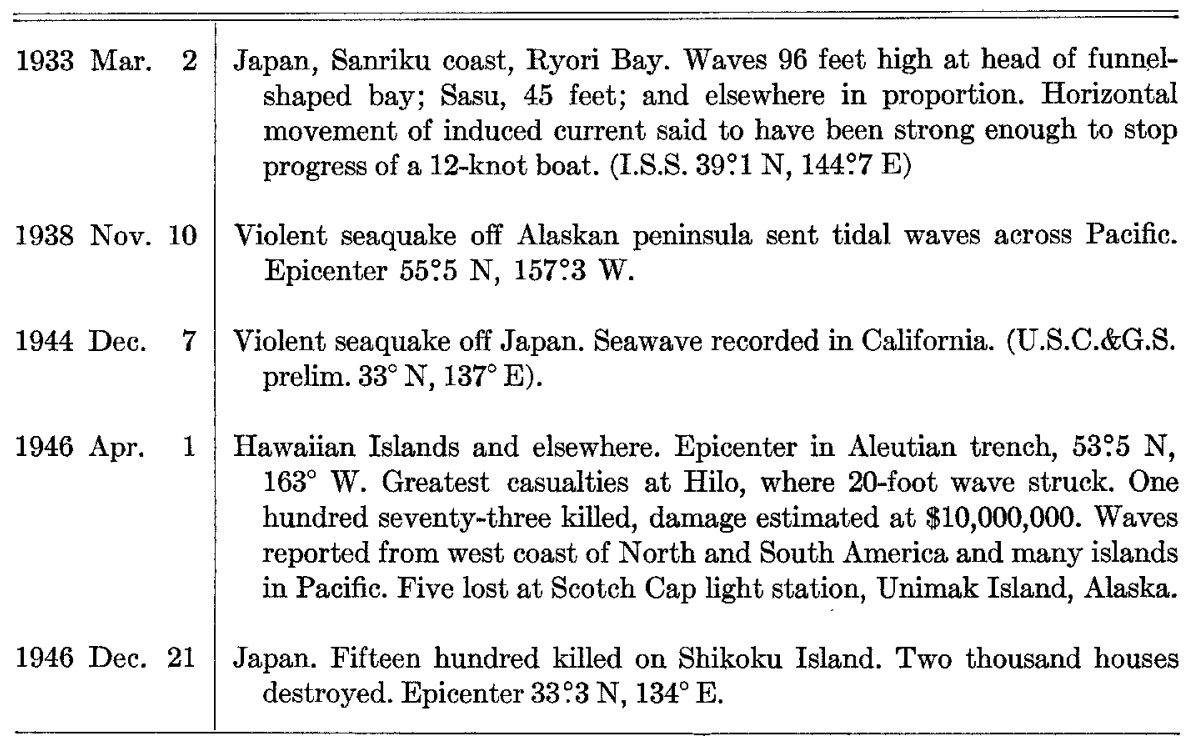

\section{Correlation between T Phase and Tsunamis}

A remarkable correlation has been found between the occurrence of the $T$ phase and the occurrence of tsunamis. ${ }^{8}$ The list of Pacific Ocean tsunamis in table 1 is taken from the list of Heck. ${ }^{9}$ It includes all entries in his list later than 1932 except six tsunamis from earthquakes which would not be expected to produce $T$ phases at the California stations owing to intervening land.

Of the tsunamis listed in table 1, all except that of April 1, 1946, produced $\mathrm{T}$ phases at the Pasadena and Berkeley networks. Furthermore, except for the earthquake of May 14, 1948, which produced no tsunami, no other T phases were produced. Hence during this period there were 5 Pacific tsunamis, of which 4 were accompanied by $\mathrm{T}$ phases, and $5 \mathrm{~T}$ phases, of which 4 were

\footnotetext{
${ }^{8}$ Tolstoy and Ewing, loc. cit.
}

${ }^{9}$ N. H. Heck, "List of Seismic Sea Waves," Bull. Seism. Soc. Am., 37:269-286 (1947). 
accompanied by tsunamis. Further study might reveal the reason for the two discrepancies.

In the Atlantic Ocean, in the period 1939-1948, only West Indian shocks produced $T$ phases recorded at Weston, Fordham, and Ottawa. The only other shocks that need be considered are those of magnitude 7 or greater on the MidAtlantic Ridge. Two were completely blocked by the Mid-Atlantic Ridge, and one was partly blocked. Unfortunately, there is no clean-cut evidence that the Mid-Atlantic shocks can produce T phases. During this interval, 20 Dominican Republic shocks produced $T$ phases. Of these, 4 had magnitudes greater than 7; all were located just north of the Dominican Republic. The 16 shocks of magnitude less than 7 are of no importance for correlation with tsunamis, being mainly small aftershocks. They have been studied in an effort to understand the great strength of $\mathrm{T}$ in comparison with $\mathrm{P}$ in this area, which is accounted for by the shorter distance, the more favorable angle of incidence upon the coast line, and possibly by other factors. Conversely, the conditions in this part of the Atlantic Ocean minimize the effects of tsunamis upon coast lines. It has often been stated that this occurs primarily through the shielding effect of the broad continental shelves and the blocking action of the MidAtlantic Ridge, but the fact that Bermuda has never experienced a destructive tsunami may be interpreted to mean less efficient generation of the gravity wave by Atlantic shocks than by Pacific shocks.

Of the 4 Dominican Republic shocks of magnitude 7 or greater, namely, those of August 4, August 8, August 21, and October 1, 1946, that of August 4 (magnitude 8) produced a destructive tsunami in the vicinity of the epicenter which was also well recorded on the tide gauge at St. George's, Bermuda. The August 8 (magnitude 7.6) shock produced a questionable record on the tide gauge at St. George's. Those of August 21 (magnitude 7.0) and October 4 (magnitude 7 ) did not produce definite evidence of a tsunami on any tide gauge in the Atlantic, so far as can be determined from examination of about a dozen records. Apparently there is good correlation between $T$ phases and tsunamis in the Atlantic, but the ratio between the two is much different from that in the Pacific. It would be necessary, but probably quite easy, to make allowance for this factor in using $\mathrm{T}$ phases for tsunami warnings.

\section{Generation of the T Phase}

If the focus is beneath the horizontal floor of the ocean, it is only by diffraction of cylindrical or spherical waves that energy can enter the ocean for normalmode propagation. This can occur to an appreciable extent only if the focus is within approximately one wave length of the ocean bottom. The theory of the effect has been worked out and will appear in a later report. The results are analagous to those of $\mathrm{Lamb}^{10}$ on the influence of depth of focus on the produc-

10 Horace Lamb, "On the Propagation of Tremors over the Surface of an Elastic Solid," Phil. Trans. Roy. Soc. London, Ser. A, Vol. 203, pp. 1-42 (1904). 
tion of Rayleigh waves, or, even more, to those of Sezawa ${ }^{11}$ on Love waves. When the ocean floor is horizontal, it is even more difficult to introduce energy into the sound channel unless the sound source is above the bottom.

For epicenters over a slope such as the continental shelf, energy from the shock can be available for either sound-channel or normal-mode propagation, the availability of the energy being greater for shocks whose foci are very near the ocean floor. But even when the foci are considerably deeper, much more energy is available than for the horizontal bottom, the inclination of the slope facilitating entrance of energy into the ocean in a manner analagous to that of the prism of the Lummer-Gehrke plate in optics.

\section{Relievant Facts and Previous Theories on Tsunamis}

Tsunamis are gravity waves of 15 to 30 minutes period, which are propagated with a velocity of approximately $\sqrt{g h}$. The wave train consists of several oscillatory waves. Tsunamis are generated by shallow-focus earthquakes, under or near the sea, particularly at steeply dipping coasts. The circumpacific earthquake belt is the principal source of destructive tsunamis.

The principal theories for generation of these large gravity waves have been submarine volcanic eruptions, submarine slumping induced by earthquakes either under the ocean or near to it, or submarine faulting, particularly that involving vertical displacements.

\section{Proposed Warning Systems}

The strong correlation between the occurrence of the $T$ phase and destructive tsunamis warrants the inclusion of instruments suitable for recording $\mathrm{T}$ in stations of a tsunami warning system. The $\mathrm{T}$ phases observed in California are probably too small for practical use. It is believed that SOFAR listening stations would receive far better signals. The relative merits of short-period seismographs on land and of hydrophones in the sound channel can be determined by an experimental station having both types of equipment.

Although many points deserve further study, the available knowledge and experience indicates that the utilization of the $T$ phase in tsunami warning systems and the possible installation of hydrophones in the sound channel to augment the present installations is justified.

\section{Some Points Which Deserve Further Study}

The relative importance of normal-mode and sound-channel propagation should be determined. The spectrum of the received signal should be explored. The effect of prolongation of a signal by propagation across land should be determined. The relation between frequency of sound in the water to that

${ }^{11}$ Katsutada Sezawa, "Love Waves Generated from a Source of a Certain Depth," Bull. Earthq. Res. Inst. (Tokyo), Vol. 13, Pt. 1, pp. 1-17 (1935). 
received at an inland station should be determined. The feasibility of accurate location of submarine epicenters through use of SOFAR triangulation should be tested.

\section{ACKNOWLEDGMENTS}

The authors wish to express their thanks to Professors B. Gutenberg and C. F. Richter, of the California Institute of Technology, for their help and coöperation in making a large number of Pasadena records available. We are also greatly indebted to Father Daniel Linehan, S.J., of the Weston Seismological Observatory, whose records went far toward making this investigation possible. Dr. E. A. Hodgson, of the Dominion Observatory of Canada in Ottawa; Professor Perry Byerly, of the University of California; Father John J. Lynch, S.J., and Dr. William A. Lynch, of Fordham University, and the Officers of the U. S. Coast and Geodetic Survey, Sections of Seismology and of Tides and Currents, were extremely helpful during this investigation.

Lamont Geological Observatory

(Columbia University),

Palisades, New York.

(Lamont Geological Observatory Contribution No. 17.) 